\title{
First Test Results on ITER CS Model Coil and CS Insert
}

N. Martovetsky, P. Michael, J. Minervini, A. Radovinsky, M. Takayasu, R. Thome, T. Ando, T. Isono, T. Kato, H. Nakajima, G. Nishijima, Y. Nunoya, M. Sugimoto, $Y$. Takahashi, H. Tsuji, D. Bessette, K. Okuno, M. Ricci, R. Maix

This article was submitted to American Nuclear Society $14^{\text {th }}$ Fusion Topical Meeting on Technology of Fusion, Park City, Utah, October 15-19, 2000

U.S. Department of Energy

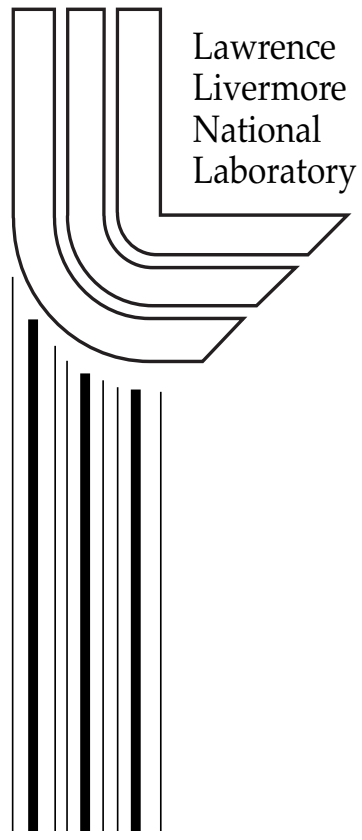

October 12, 2000 


\section{DISCLAIMER}

This document was prepared as an account of work sponsored by an agency of the United States Government. Neither the United States Government nor the University of California nor any of their employees, makes any warranty, express or implied, or assumes any legal liability or responsibility for the accuracy, completeness, or usefulness of any information, apparatus, product, or process disclosed, or represents that its use would not infringe privately owned rights. Reference herein to any specific commercial product, process, or service by trade name, trademark, manufacturer, or otherwise, does not necessarily constitute or imply its endorsement, recommendation, or favoring by the United States Government or the University of California. The views and opinions of authors expressed herein do not necessarily state or reflect those of the United States Government or the University of California, and shall not be used for advertising or product endorsement purposes.

This is a preprint of a paper intended for publication in a journal or proceedings. Since changes may be made before publication, this preprint is made available with the understanding that it will not be cited or reproduced without the permission of the author.

This report has been reproduced directly from the best available copy.

Available electronically at http://www.doc.gov/bridge

Available for a processing fee to U.S. Department of Energy

And its contractors in paper from

U.S. Department of Energy

Office of Scientific and Technical Information

P.O. Box 62

Oak Ridge, TN 37831-0062

Telephone: (865) 576-8401

Facsimile: (865) 576-5728

E-mail: reports@adonis.osti.gov

Available for the sale to the public from

U.S. Department of Commerce

National Technical Information Service

5285 Port Royal Road

Springfield, VA 22161

Telephone: (800) 553-6847

Facsimile: (703) 605-6900

E-mail: orders@ntis.fedworld.gov

Online ordering: http:/ / www.ntis.gov/ordering.htm

\section{OR}

Lawrence Livermore National Laboratory

Technical Information Department's Digital Library

http: / / www.llnl.gov/tid/Library.html 


\section{ABSTRACT}

The Inner and Outer modules of the Central Solenoid Model Coil (CSMC) were built by US and Japanese home teams in collaboration with European and Russian teams to demonstrate the feasibility of a superconducting Central Solenoid for ITER and other large tokamak reactors. The CSMC mass is about $120 \mathrm{t}$, OD is about $3.6 \mathrm{~m}$ and the stored energy is $640 \mathrm{MJ}$ at $46 \mathrm{kA}$ and peak field of $13 \mathrm{~T}$. Testing of the CSMC and the CS Insert took place at the Japan Atomic Energy Research Institute (JAERI) from mid March until mid August 2000. This paper presents the main results of the tests performed.

\section{INTRODUCTION}

$\mathrm{T}$

HE CSMC and three insert coils were among the main deliverables from the ITER Engineering Design Activity, which started in 1992.

The $180 \mathrm{t}$ test assembly consists of an Inner Module ${ }^{1}$, Outer Module ${ }^{2}$, the CS Insert $^{3}$ and the supporting structure (see Fig.1). This is the largest cable-in-conduit conductor (CICC) magnet ever built with $640 \mathrm{MJ}$ stored energy at $46 \mathrm{kA}$. It operates at a higher current than any other large superconducting magnet.

The CSMC conductor used a heavy wall conduit, made from Incoloy 908 superalloy, which helped to utilize the superconducting properties of $\mathrm{Nb} 3 \mathrm{Sn}$ to full extent.

The main objectives of the testing were validation of all ITER CSMC specifications, determination of the operational limits and verification of the design criteria for superconducting magnets for fusion.

The main goals of the test program were ${ }^{4}$ :

1. Produce $13 \mathrm{~T}$ peak field in DC and a ramp mode of $0.4 \mathrm{~T} / \mathrm{s}$, consistent with ITER CS operation, with a peak current of $46 \mathrm{kA}$.

2. Demonstrate operation of the CS Insert in the reverse mode at $-40 \mathrm{kA}$ in $13 \mathrm{~T}$

3. Demonstrate a margin of $2 \mathrm{~K}$ in a simulated ITER operational scenarios.

4. Demonstrate that the CSMC can withstand high voltage discharge in a ITER relevant discharge mode, including 5-s quench detection time.

5. Demonstrate stable operation of leads and joints.

6. Study losses, ramp rate limitation, stability against thermal disturbances, quench propagation and thermohydraulic characteristics, and sensitivity to cyclic operation.

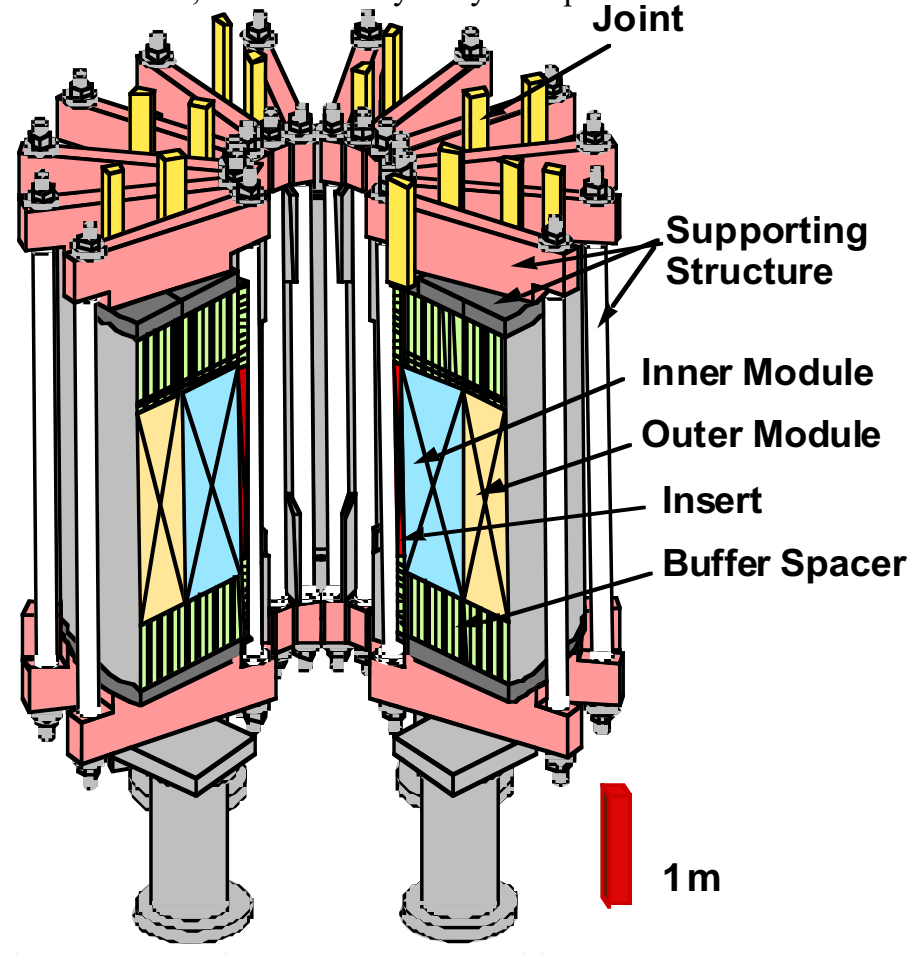

Fig. 1 CSMC and CS Insert test assembly

The CSMC and the CS Insert were installed in the CSMC Test Facility at JAERI in October 1999. From April 11 to August 18, 2000 the CSMC and the CS Insert were under test with current. About 350 experimental runs were performed in these

This Work supported by the US Department of Energy under contract to the UC Lawrence Livermore National Laboratory (contract No. W-7405-Eng-48) also under MIT Grant No. DE-FC02-93ER54186-D\&T, and by Japanese government. 
tests. More than 400 sensors were used to acquire data and the amount of information stored during the test campaign is huge. This paper presents some of the first post-test analysis results.

\section{COOLDOWN AND THERMOHYDRAULICS}

The cool down started on March 13 and the coils became superconducting on April 4. The first charging of the coil was on April 11.

The cool down time was in line with the prediction of 600 hours, limited by the tie rod temperature.

A typical flow distribution through the conductors in the CSMC is reasonably uniform as shown in Fig. 2.

The supercritical pump provided a very steady flow with total capacity in excess of $500 \mathrm{~g} / \mathrm{s}$. Most of the experiments were conducted with a flow distribution close to the one shown in Fig. 2, however, elevated temperature measurements sometimes required lower flow - down to $2 \mathrm{~g} / \mathrm{s}$ in the conductors, which were heated.

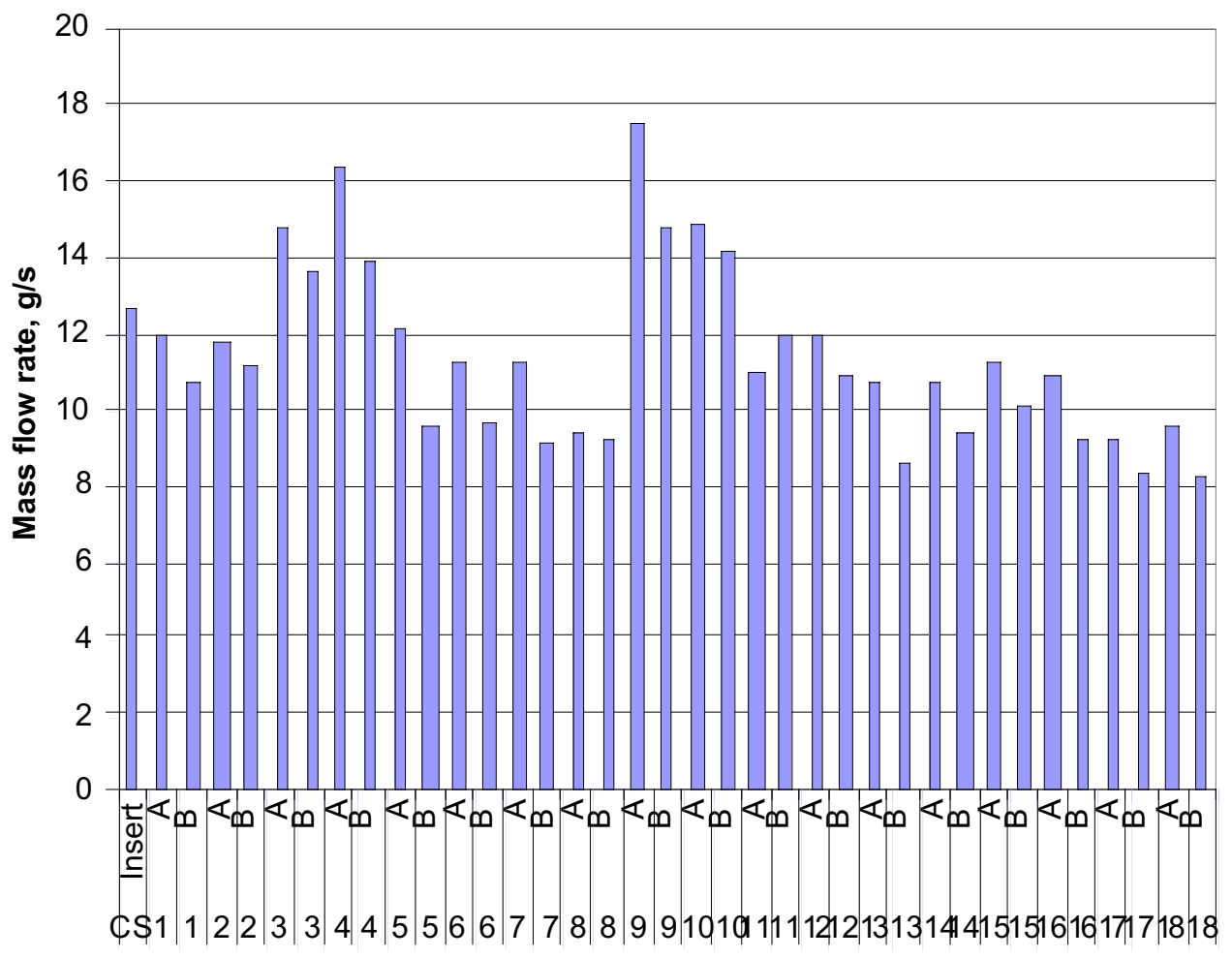

Fig. 2. Helium mass flow distribution in the CSMC and the CS Insert

\section{DC PERFORMANCE OF THE CSMC AND THE CS INSERT}

\section{A. CSMC}

The DC tests were planned to demonstrate that the available technology is capable of producing a magnet, which would fully utilize the superconductor properties in a very high field and stress environment.

The first charge to the full current of $46 \mathrm{kA}$ took place on April 19 without training. Several charges to $46 \mathrm{kA}$ at elevated temperature of $5.3 \mathrm{~K}$ were performed later to demonstrate that the magnet designed with $2 \mathrm{~K}$ margin is capable of reaching $100 \%$ of its rated current with no problem.

Current sharing temperature $\left(\mathrm{T}_{\mathrm{cs}}\right)$ and critical current measurements were carried out on conductors 1a, 11a and the CS Insert. Conductors were wound "two-in-hand", hence each layer has "a" and "b" conductors.

1. Conductors 1a and 11a Tes.

Current sharing temperature $T_{\mathrm{cs}}$ and critical current $\mathrm{I}_{\mathrm{c}}$ measurements under DC conditions showed that the superconducting properties of layer 1, and of conductor 1a in particular, follow the ITER design guidance ${ }^{6}$ based on L. Summers correlation ${ }^{7}$. Fig. 3 shows DC results measured on the layer 1. As seen from Fig.3, the current sharing measurement at constant current is consistent with the critical current measurement at a fixed temperature, which is evidence that the conductor properties reach its ultimate limit. The fitting parameters, describing the properties of the layer 1a are: $\mathrm{jc}=593 \mathrm{~A} / \mathrm{mm}^{2} @ 4.2 \mathrm{~K}, 12 \mathrm{~T}$, e= $0.25 \%, \mathrm{Tc} 0 \mathrm{~m}=18 \mathrm{~K}, \mathrm{Bc} 20 \mathrm{~m}=28 \mathrm{~T}$ ).

These fitting parameters show that the CSMC conductor exceeds the specified strand current density at $12 \mathrm{~T}$ and $4.2 \mathrm{~K}$ of 
$550 \mathrm{~A} / \mathrm{mm}^{2}$. The cable experienced a very low strain in the conductor resulting in high jc because of Incoloy 908 conduit and a proper design.

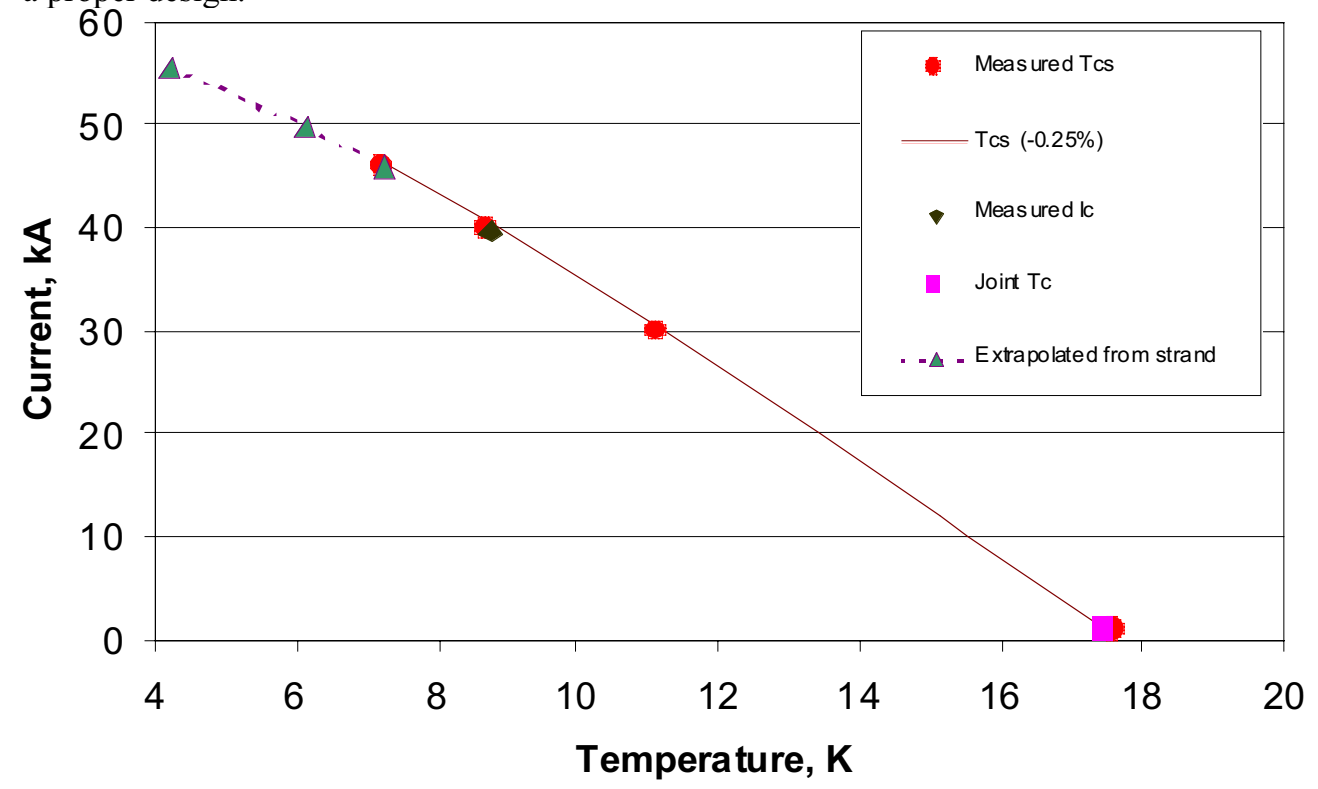

Fig. 3. Results of the DC tests on the layer 1 and a fitting curve ${ }^{6}$.

2. Layer 11a

Measurement results for layer 11a are summarized in Fig. 4. The critical current of layer 11a shows higher parameters than expected from the strand specifications or from the short sample data, which are higher than the specifications. Also, it was noted that the measured data do not fit well into a L. Summers correlation ${ }^{7}$ within a reasonable range of parameters. It is possible, that since the conductor 11a has a mixture of two different strands (Hitachi and Furukawa), the behavior of the Tcs in a mixed cable is different than for a single strand cable. These facts are yet to be analyzed in more detail. Nevertheless, it seems clear that conductor 11a does not show any sign of degradation.

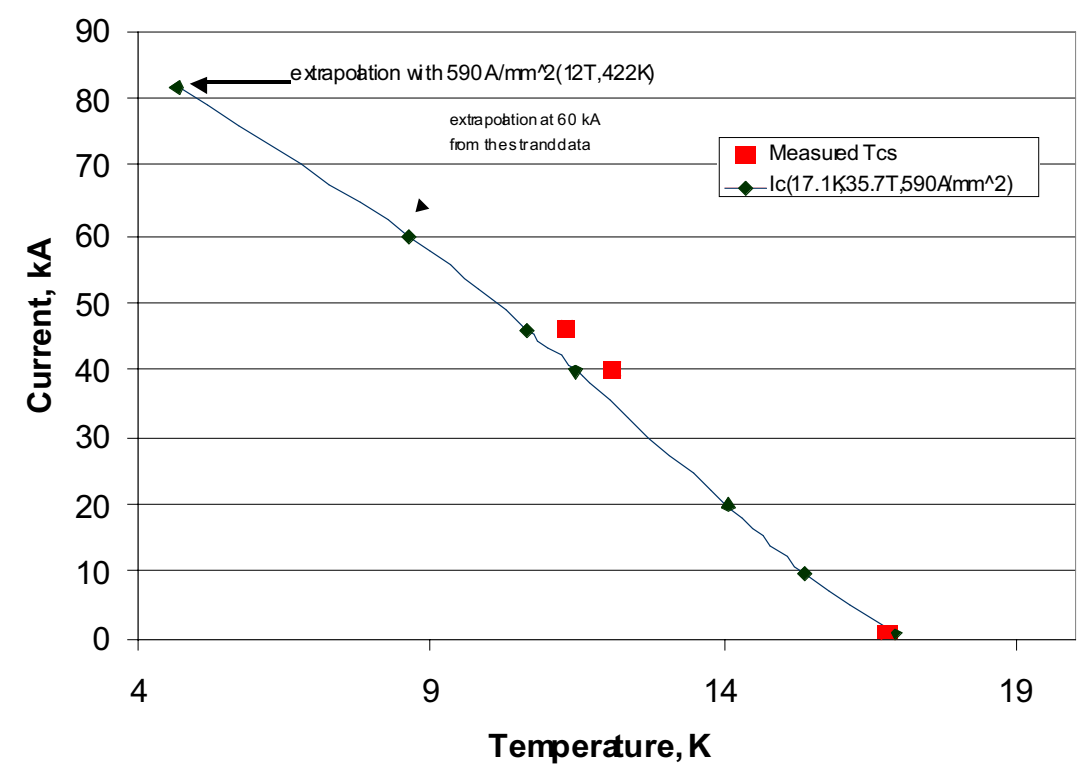

Fig. 4. Current sharing measurements on the conductor 11a

3. CS Insert

The $T_{c s}$ and $I_{c}$ were measured on the CS Insert in 13T by varying the background field from the CSMC. The $T_{\text {cs }}$ at $13 \mathrm{~T}$ and 40kA, (nominal operation conditions of ITER-EDA) was 7.7K.

This satisfies the requirement of the temperature margin of $2 \mathrm{~K}$ for the maximum operating temperature of $5.3 \mathrm{~K}$. The measurement results exceed the ITER design guidance as shown in Fig. 5. However, even better properties were expected from the strand data, since $\mathrm{j}_{\mathrm{c}}$ in a strand sample heat treated with the CS Insert was higher than the $550 \mathrm{~A} / \mathrm{mm} 2$ of the ITER design guidance by $20 \%$. Although more detailed analysis is needed to finalize the conclusion, it is clear that the CS Insert 
showed small degradation due to manufacture. Later in the tests some degradation of properties was observed during cyclic testing of the CS Insert.

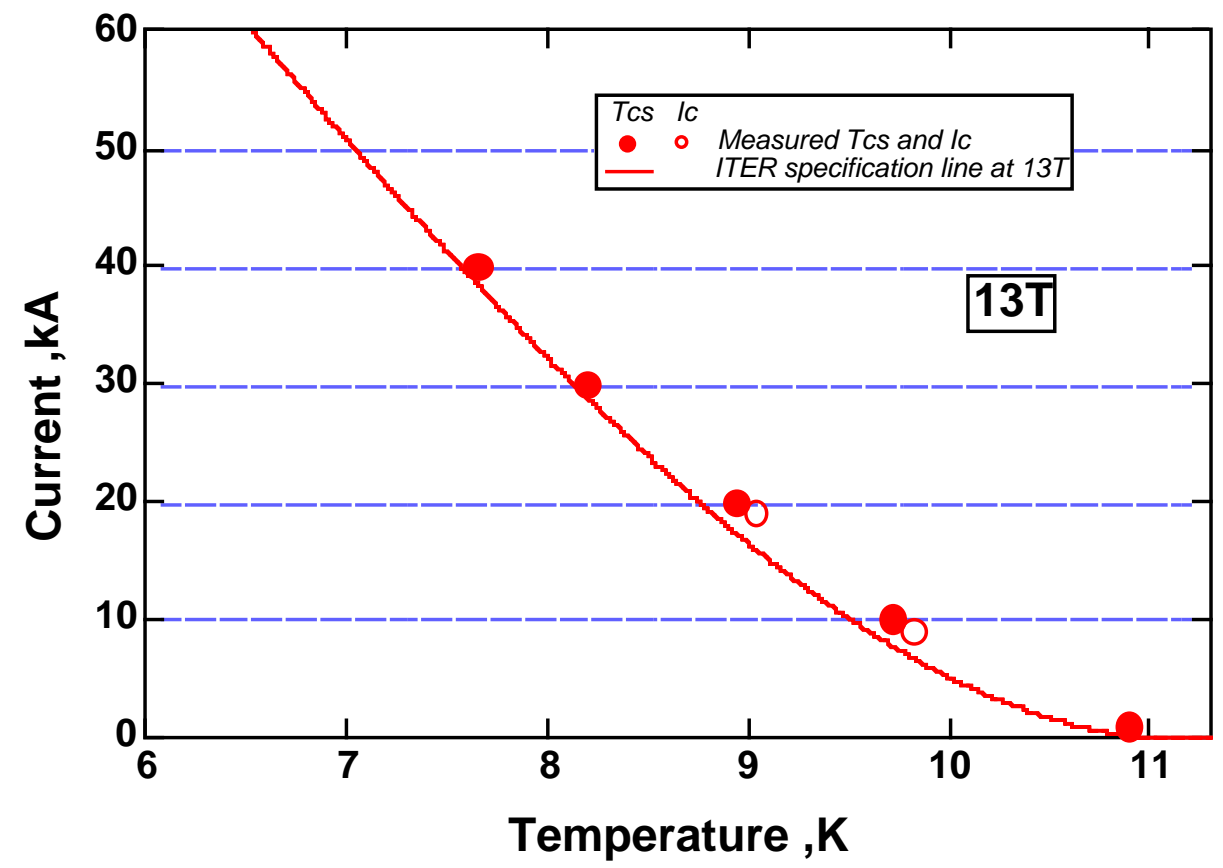

Fig. 5. Current sharing temperature and critical current measured in the CS Insert Coil.

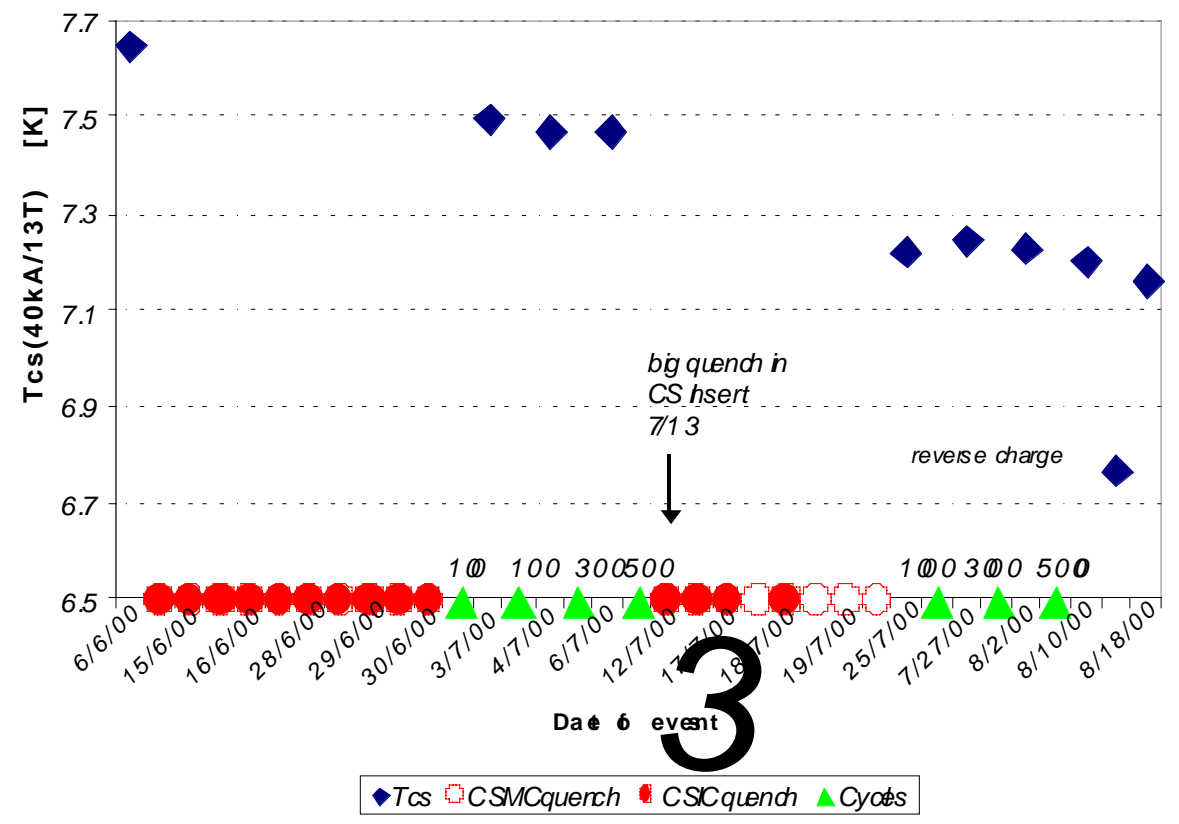

Fig.6 CS Insert current sharing temperature evolution

\section{CYCLIC TESTING OF THE CS INSERT}

A cycling test on the CS Insert was performed for 10003 cycles. The cycling took place in the background field of about 13 $\mathrm{T}$, provided by the CSMC and the CS Insert current varied between 0 and $40 \mathrm{kA}$ in triangular cycles. This test simulated cycling loading, which the ITER CS coil will experience in operation. The current sharing temperature $\mathrm{T}_{\mathrm{cs}}$ was measured at $13 \mathrm{~T}$ and $40 \mathrm{kA}$ many times: before the cycling test runs and after 100, 200,500,1000, 2000, 5000 and 10,000 cycles, respectively. Fig. 6 shows variation of the Tcs versus time, showing several other events besides cycling tests that took place in this time span. From Fig. 6 one may speculate that it is not the cycling, which caused an apparent decrease in the Tcs, but, possibly, one of the quenches, which were initiated in the pulsed tests in between the cyclic loading tests. This phenomenon is not fully understood yet. The hot spot temperature in the CS Insert is designed not to exceed $150 \mathrm{~K}$. The quench 
temperature of the conductor jacket was measured at $65 \mathrm{~K}$ and computer simulations did not predict large temperature differences between the cable and the conduit, so direct temperature influence of the quench on the NbSn properties is unlikely. One of the speculations - that a fast temperature change can cause a permanent change in the mechanical condition of the cable - needs a credible modeling and testing. More studies are, therefore needed to explain the observed Tcs degradation.

\section{JOINTS}

The joints in any high current magnet like the CSMC and the CS Insert are very important elements, which could have become the limiting factor in the CSMC overall performance. Two types of $46 \mathrm{kA}$ joints for the CSMC were developed and tested during an extensive $R \& D$ program ${ }^{8,9}$ : a lap joint and a butt joint. The requirements to have a low resistance, low DC and $\mathrm{AC}$ losses and high reliability in a high field and high $\mathrm{dB} / \mathrm{dt}$ environment made the joints quite complicated. Only a few cryogenic tests on prototypes were carried out to verify the joint performance in the R\&D effort and some improvements were made. The number of joints fabricated for the CSMC exceeded the R\&D production by an order of magnitude and, since during the R\&D stage we had a few joints, which failed to meet the specifications, there was a concern about possibility of a sub-standard joint in the test assembly. The CSMC testing was truly a verification test that provided very valuable data on the joint performance in the large magnet.

The R\&D effort on the joints showed, that electrical measurements made across the joints indicated a significantly lower heat generation than the real heat generation in the joint measured by calorimetry. This was caused by the current distribution near the joint in the relatively short test samples. In the CSMC it was expected that the current distribution would be more favorable due to the longer distance between joints.

Fig. 7 shows resistance of the joints measured by two independent ways - by electrical and by calorimetric methods.

It is seen that both joint designs (lap joints in layers $1-10$ and

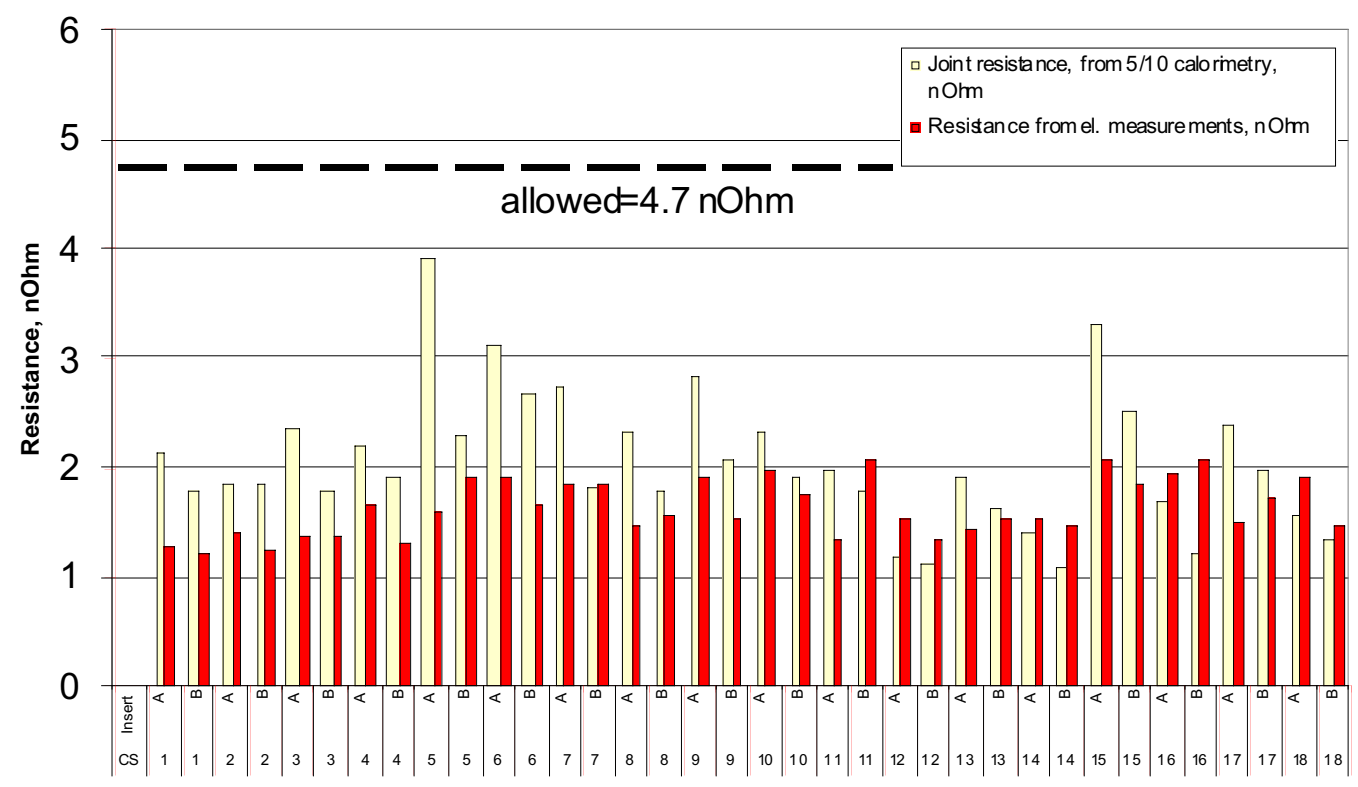

Fig. 7 Joint resistances in the CSMC and the CS Insert measured by electrical and calorimetry methods at $46 \mathrm{kA}$

butt joints in layers 11-18) provided resistances below the specifications in a quite reproducible manner. The two methods give very consistent and close results, much closer than in the short sample measurements during the R\&D on the joints.

These results show that the R\&D effort on the joints was successful and show that the high current, low resistance, low loss joints can be built in an industrial environment reliably. In no test runs at $4.5 \mathrm{~K}$, did the joints cause a quench or limit performance.

\section{AC LOSSES}

Loss measurements in the CSMC and the CS Insert were one of the most important elements of the Test Program. It was known from previous experiments that the short sample loss measurements do not always represent the losses in the 
magnet ${ }^{10}$. The scatter in the loss measurements on the short samples of relevant subscale and full-scale ITER conductors during the R\&D effort was very significant. The coupling loss time constant varied from several milliseconds to $30-50 \mathrm{~ms}$ per unit of strand volume ${ }^{11-13}$. It also varied greatly depending on mechanical load on the conductor and number of test cycles. In a 1-m OD CIC Nb3Sn magnet test it was noticed that the losses decreased significantly as a result of the charge cycles ${ }^{14}$. The same results were observed in the conductor samples ${ }^{15}$. Looking for this effect, the losses in the CSMC and the CS Insert were measured periodically starting from the first shots until the very end of the test campaign. Many interesting phenomena were observed during AC loss measurements; here we are presenting only a few major results.

A. Hysteresis losses.

The hysteresis losses in the conductors were measured in very slow ramps $(\mathrm{dI} / \mathrm{dt}=1 \mathrm{kA} / \mathrm{min})$.

Fig. 8 presents the measured losses in the CSMC conductors and in the CS Insert in comparison with the measured losses in the strands. In some cases only few samples per conductor were measured. To show the extremes in the strand data we used minimum and maximum strand loss and assumed that the whole cable is made of either a low loss or a high loss strand. The losses in the strand were calculated in the standard cycle between $3 \mathrm{~T}$ and $(-3 \mathrm{~T})$ and were recalculated for comparison with the real trapezoidal cycle performed in the test. From Fig. 8 one can see that the expected hysteresis losses

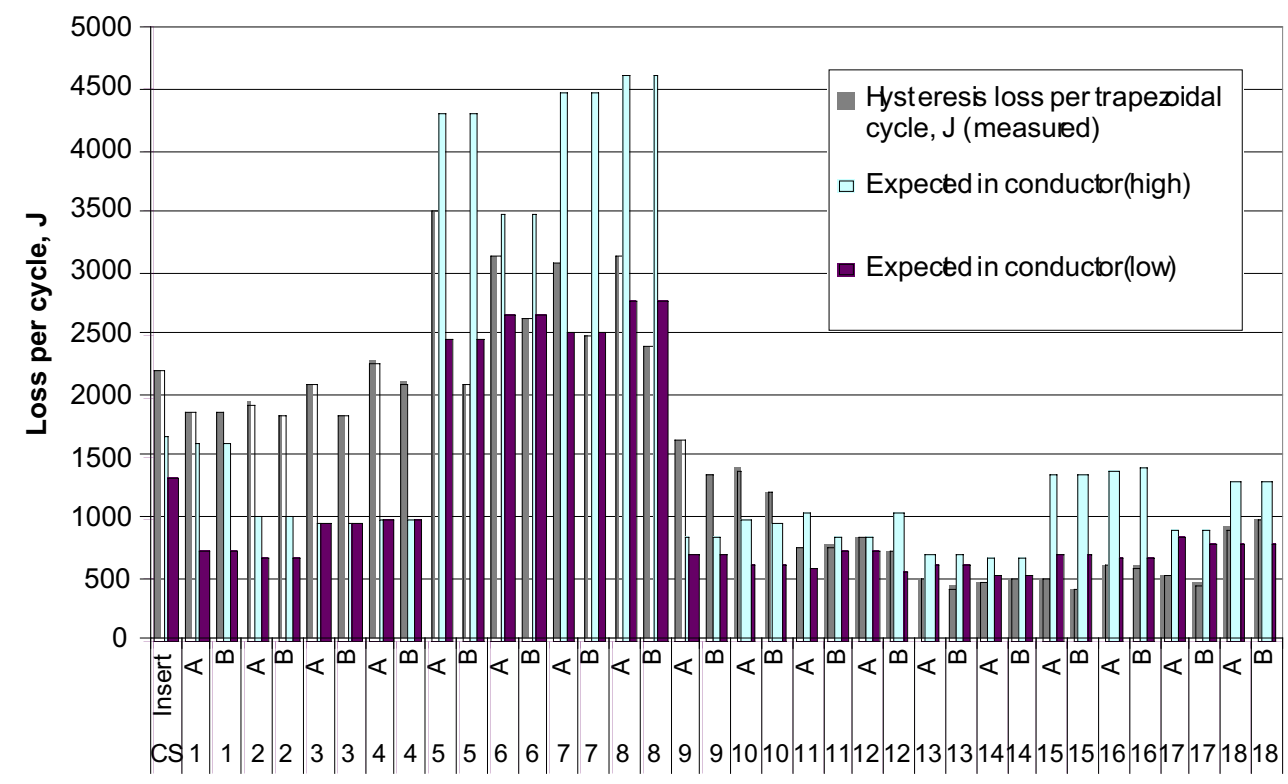

Fig.8 Distribution of the hysteresis losses in the CSMC and the CS Insert conductors in the trapezoidal waveform run to 9.2 $\mathrm{kA}$

are in general close to the measured hysteresis losses, especially for the Outer module. The CS1 conductor in layers 1-4, which employed Vacuumschmelze strand showed somewhat higher losses than was expected from the strand measurements.

The IGC strand, used in the layers 5-8, and the Mitsubishi strand in the layers 10, 15 and 16, which were made by the internal tin process, showed lower than expected hysteresis losses. This indicates that the internal tin strand is a viable candidate for any layer, including the inner layers of the Central Solenoid for a future fusion machine.

Since measured hysteresis losses include losses in the joints; the measurement data suggest that the losses in the joint at slow rates are relatively low, fraction of one Watt, even for Inner Module. The fact that the measured losses are close to the hysteresis losses in the strands also suggests that there are no loops with long coupling time constants in the CSMC conductors. Such loops were observed in a $\mathrm{NbTi} \mathrm{CICC}^{10}$, where these loops with long time constants were responsible for significant increase in losses at slow ramp rates.

\section{B. Coupling losses}

The coupling loss time constants for all conductors in the CSMC and the CS Inserts deduced from the $18 \mathrm{~s}$ discharge from $36.8 \mathrm{kA}$ on June 26 are shown in Fig.9.

The coupling losses in the CSMC showed several interesting features:

Most of the conductors, except the CS Insert show significant and more or less monotonic reduction in losses (factor of 2 to 3 from the virgin state) with time and number of cycles.

The coupling loss constant for the Inner Module conductors is noticeably lower than for the Outer Module conductors, especially for the layers $14-16$.

One of the possible explanations for the loss reduction is the electromagnetic load on the cable, which breaks the low 


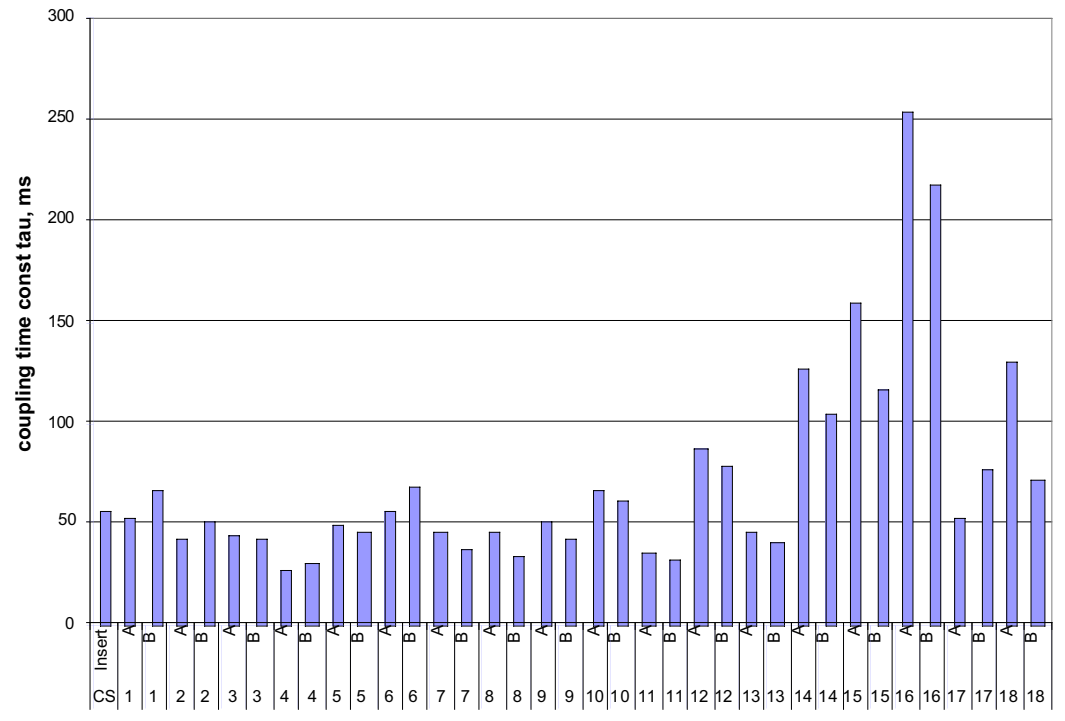

Fig. 9. Coupling time constant in the CSMC and CS Insert measured on 6/27/00

resistance links between strands. Trying to find a quantitative correlation between number of cycles and the coupling losses, we introduced a term for the equivalent elapsed number of cycles Np. The Np equals to the summation of $\left(\mathrm{B}_{\mathrm{i}} / \mathrm{B}_{1}\right)\left(\mathrm{I}_{\mathrm{p}} / 46\right)^{2}$ values, , where $\left(B_{i} / B_{1}\right)$ is the ratio between the average field in the layer "i" $i$ "and in the layer $1, I_{p}[k A]$ is the peak current in each test run. So, for example, a charge to $23 \mathrm{kA}$ would contribute in the first layer 0.25 to the $\mathrm{Np}$, while full charge to $46 \mathrm{kA}$ will contribute 1, respectively smaller in the outer layers. Fig. 10 shows a correlation for the Inner Module selected layers, all of which seem to follow the same pattern. Fig. 11 shows the reduction of the coupling losses in the three selected conductors of the Outer module. As one can see, the saturation of the losses is reached in 5-10 cycles for most of the conductors, although some (15A for example) need more cycles to come to a balance.
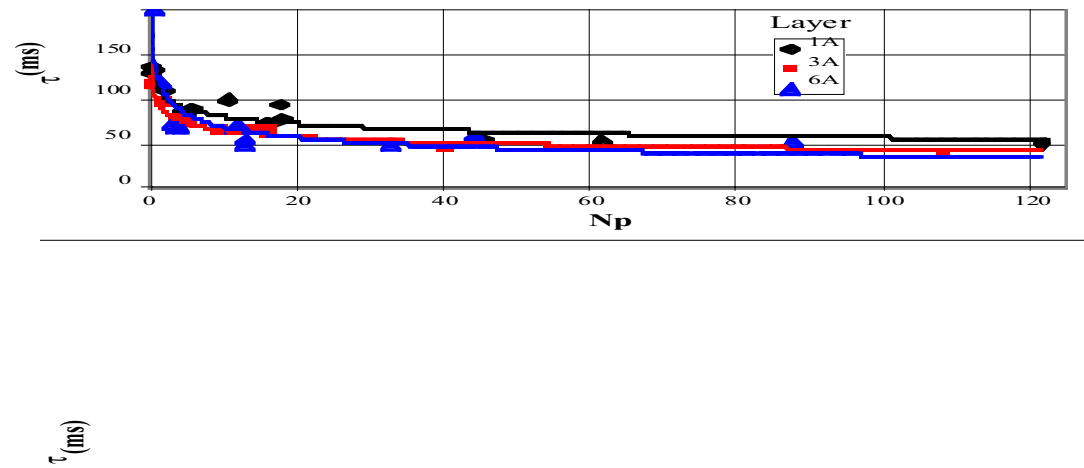

Fig.10. Reduction of the coupling loss in selected conductors of the inner module with number of equivalent cycles (see text for details)

The CS Insert loss measurements showed very different behavior.

Fig. 12 shows the traces of the product of enthalpy difference and mass flow $n_{\text {in }}\left(h_{\text {out }}-h_{\text {in }}\right)$, which constitute the losses in the conductor, when integrated over time between equilibrium states before and well after the run. All of the runs were taken in the same identical conditions - the CSMC 


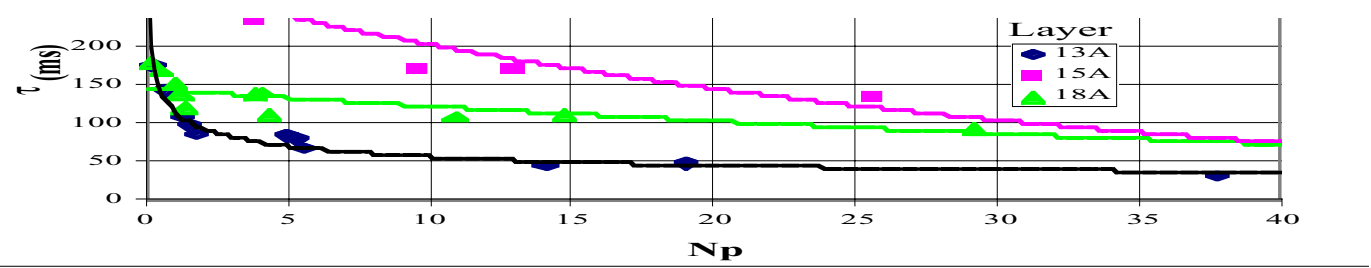

Fig.11. Reduction of the coupling loss in the outer module with number of equivalent cycles (see text for details)

was charged to $36.8 \mathrm{kA}$ and after about $1500 \mathrm{~s}$ of the flat top, the CSMC was discharged into a dump resistor with a decay time of about $18 \mathrm{~s}$. The CS Insert was open, so no transport current could flow in the CS Insert. These runs were taken at different moments of the test campaign - from mid April to mid August.

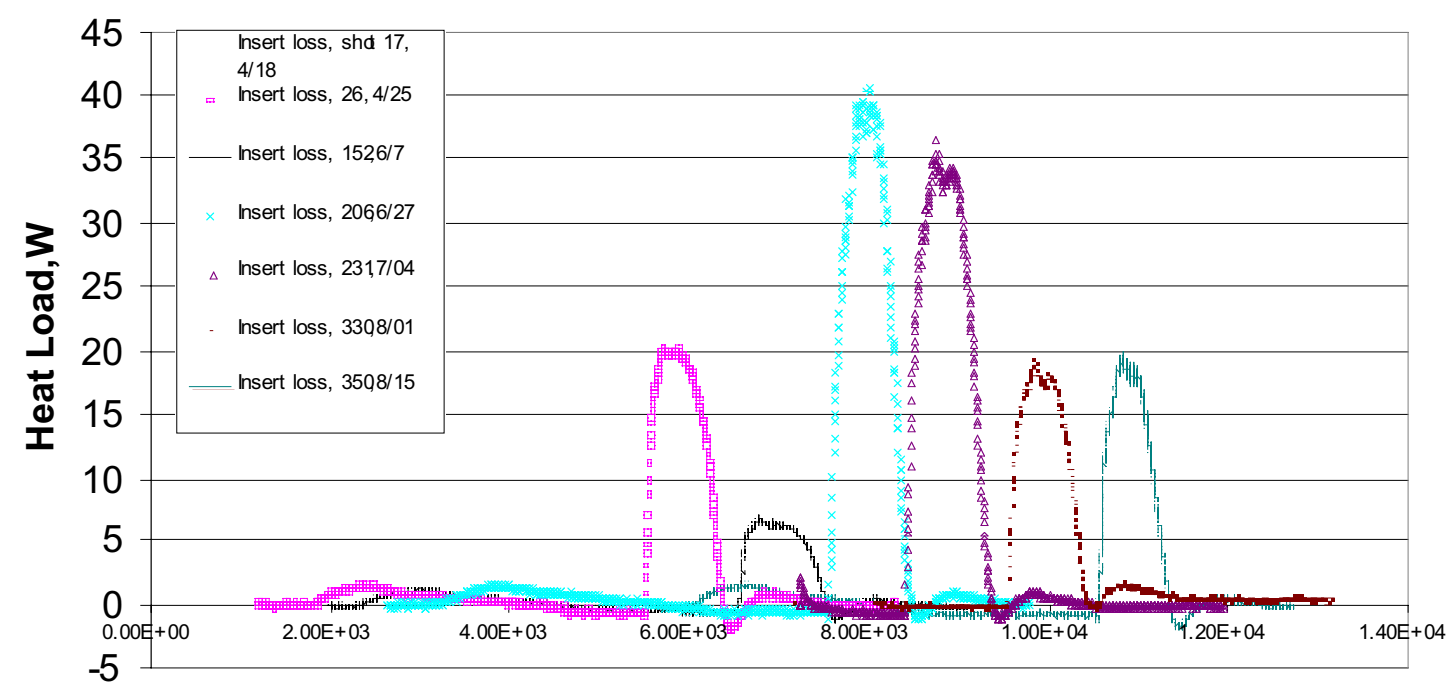

Time, s

Fig.12. Calorimetric traces of losses in the insert in $18 \mathrm{~s}, 36.8 \mathrm{kA}$ discharges 


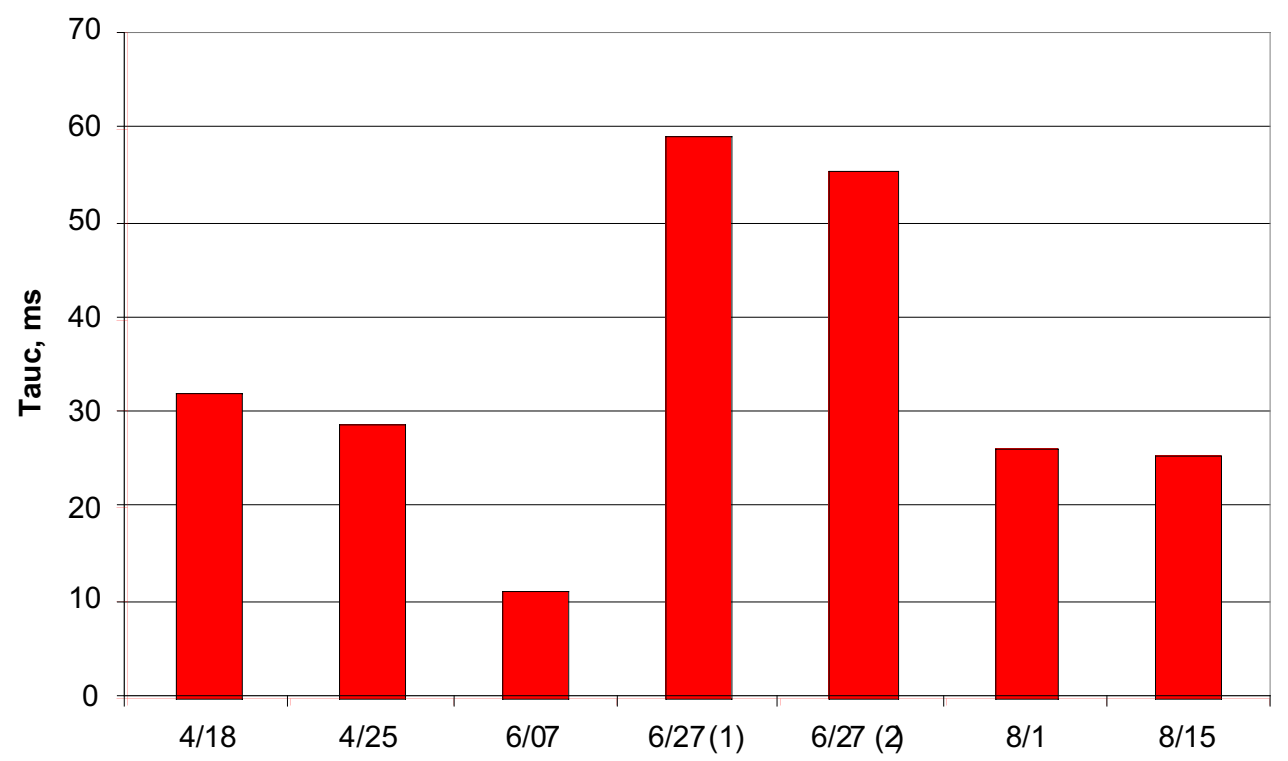

Fig.13 Coupling time constant, $\tau \mathrm{c}$ in the CS Insert deduced from $36.8 \mathrm{kA} 18 \mathrm{~s}$ dumps, shown in Fig.12

Fig. 12 and 13 show that the coupling losses in the beginning of the test campaign were slightly reducing in time. In this period, before June $1^{\text {st }}$, the transport current was never introduced into the CS Insert. Testing with transport current in the CS Insert started on June 1, 2000 and loss measurements made on June 6 showed significant reduction of the coupling losses. After several tests with transport current in the CS Insert the losses were re-measured on June 27 (see Fig.12-13). The growth of the coupling time constant by a factor of almost 6 (see Fig. 13) was not expected. This was opposite to the CSMC behavior. In the CS Insert losses increased after applying the electromagnetic forces to the cable. In subsequent testing, where the CS Insert underwent many tests, including charging for 10000 cycles, the coupling losses decreased significantly and came to an apparent saturation at the level of the original "virgin" state. To our knowledge, this highly non-monotonic behavior was not observed in short samples or in magnets before.

This phenomenon deserves further investigation, since the apparently unpredictable behavior of the losses suggests a requirement of a high safety margin for coupling loss allowance in CICC magnets designed for future machines.

4. Effect of transport current on coupling losses

The effect of transport current on the losses in the CS Insert was studied by comparison of losses in two consecutive shots, with a slow charge of the CSMC to $36.8 \mathrm{kA}$, then with the flat top of about $1500 \mathrm{~s}$ and a fast discharge with a constant time of $18 \mathrm{~s}$. Fig. 14 shows the traces of the loss power measured in the CS Insert. The only significant difference comes from the Joule heat in the joints during the slow charge when the CS Insert has a current in it

Some other test runs, involving high $\mathrm{dB} / \mathrm{dt}$ operation, revealed significant effects of the transport current on the AC losses. For example, in a trapezoidal waveform pulse to $13 \mathrm{~T}$ with a ramp up rate of $0.4 \mathrm{~T} / \mathrm{s}$, flat top of $5 \mathrm{~s}$ and ramp down rate of $0.67 \mathrm{~T} / \mathrm{s}$ the losses in the CS Insert with transport current in series with the CSMC were about two times higher than with no current in the CS Insert.

These seemingly contradictive observations remain to be explained in the future analysis and possibly tests. 


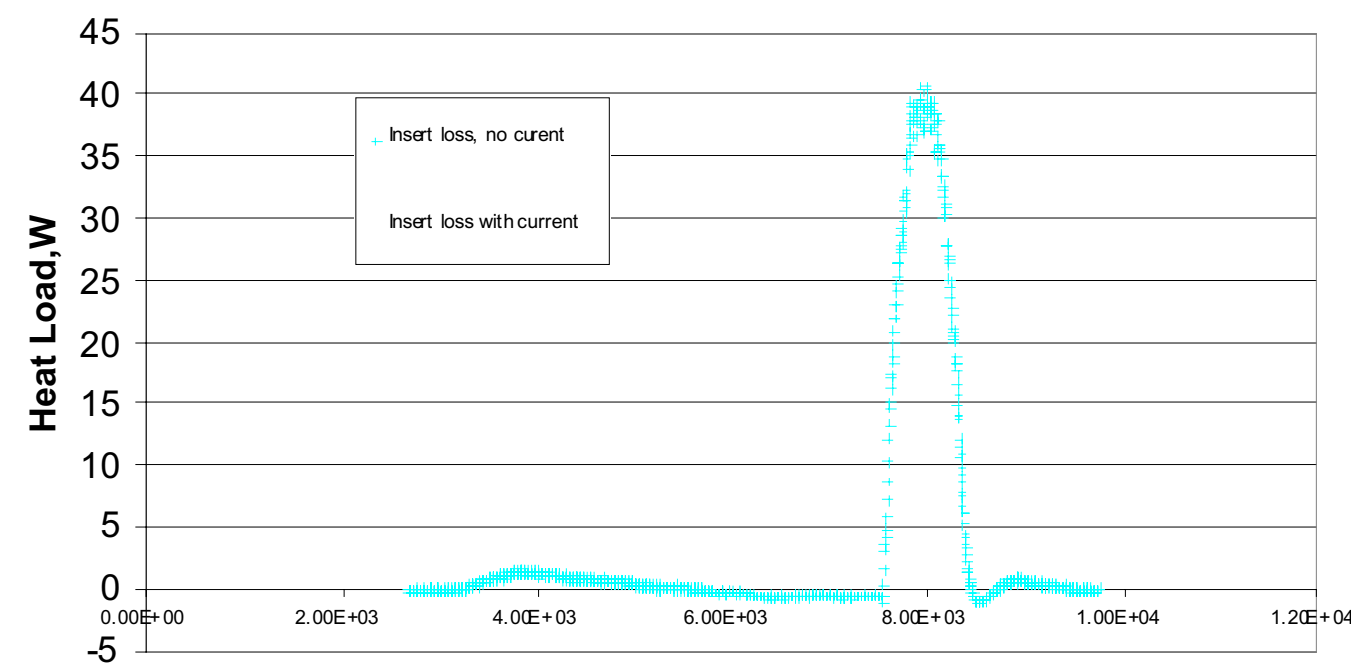

Time, $\mathbf{s}$

Fig. 14. Effect of transport current on losses in the CS Insert: 80\% discharge with $18 \mathrm{~s}$ dump time on 6/27

\section{RAMP RATE LIMITATION}

The nominal ramp rate for the CSMC design was $0.4 \mathrm{~T} / \mathrm{s}$ for a charge to $13 \mathrm{~T}$. The pre-test analyses predicted that the maximum ramp rate, which the CSMC and the CS Insert would be able to withstand with no margin was about $1.2 \mathrm{~T} / \mathrm{s}$.

The CS Insert withstood the $1.2 \mathrm{~T} / \mathrm{s}$ ramp to $13 \mathrm{~T}$, while CSMC conductor $1 \mathrm{~b}$ quenched in that run at about $11.8 \mathrm{~T}$ due to slightly higher and less uniform losses than in the CS Insert. This is very close to the pre-test analysis prediction.

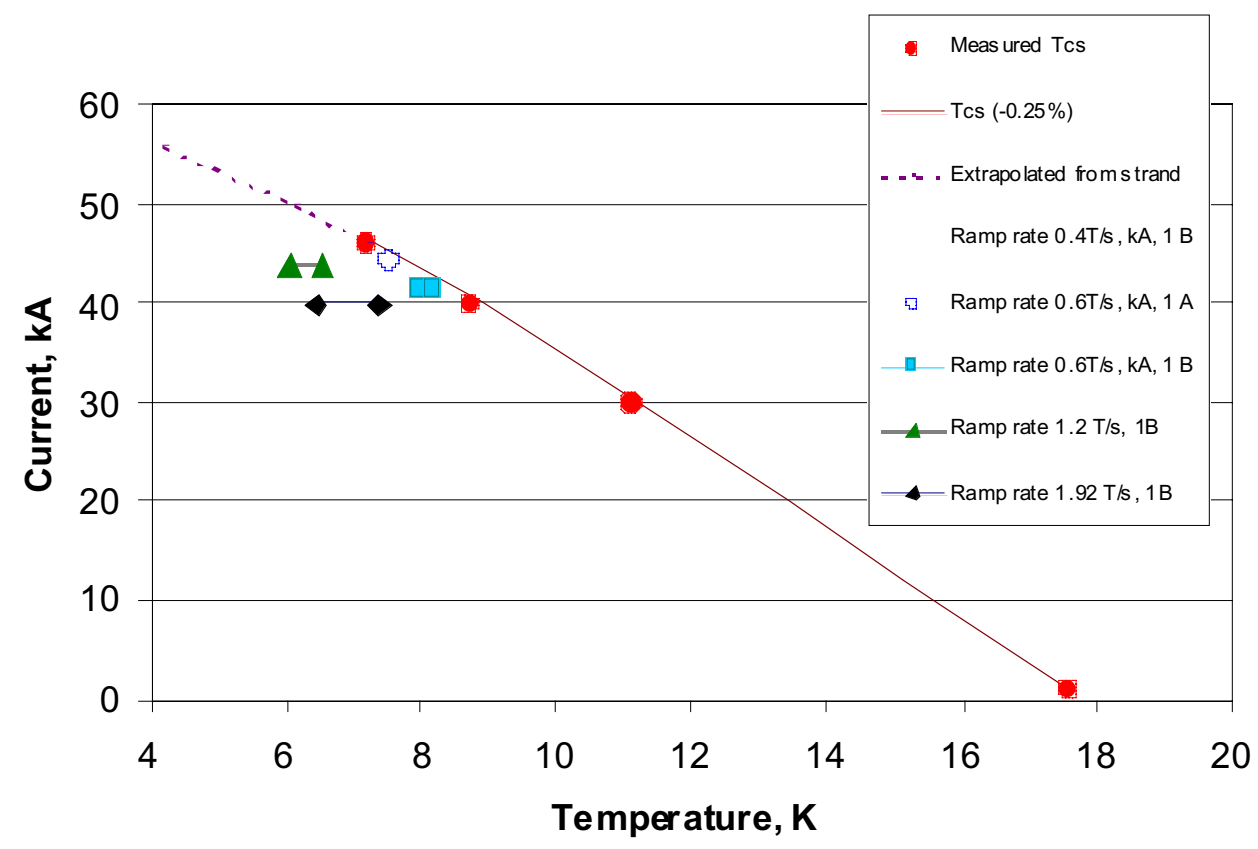

Fig.15. Peak temperature prior to quenches in the pulses versus DC current sharing temperature Tcs

The CSMC was successfully charged to $38 \mathrm{kA}$ at $1.9 \mathrm{~T} / \mathrm{s}$; the CS Insert had to be warmed to $6.5 \mathrm{~K}$ to quench it at $40 \mathrm{kA}$ and $1.9 \mathrm{~T} / \mathrm{s}$ ramp. To establish if quench in the CSMC at high $\mathrm{dB} / \mathrm{dt}$ results from instability or from simple heating due to losses, we calculated the maximum temperature in the conductor at the moment of the quench. We used no-quench runs and the outlet/inlet data for the analysis. Fig. 15 shows the result and indicates that the losses and corresponding heating are mostly responsible for the quench and electromagnetic instability and non-uniform current distribution in the conductor play a small role up to $0.6 \mathrm{~T} / \mathrm{s}$. The deviation from the DC performance starts to grow at higher $\mathrm{dB} / \mathrm{dt}$ rates. These results and 
many other successful runs simulating the ITER operation scenarios, including plasma initiation, disruptions and much more severe conditions showed that the CSMC had relatively low ramp rate sensitivity up to $2 \mathrm{~T} / \mathrm{s}$.

\section{QUENCH PROPAGATION}

\section{A. Propagation of the normal zone}

A study of the quench propagation and temperature development was performed on the CS Insert, equipped with an inductive heater, temperature sensors and a pressure sensor in the high field area. The inductive heater was used to initiate a quench and voltage taps, thermometers and the pressure tap provided information regarding the quench development. During these tests it was demonstrated that the CS Insert could be discharged with a nominal $5 \mathrm{~s}$ delay and $20 \mathrm{~s}$ discharge time with no problem. The maximum temperature in the cable, estimated by the cable resistance did not exceed $90 \mathrm{~K}$, the conduit temperature before dump did not exceed $25 \mathrm{~K}$. The pressure growth due to the normal zone propagation and the losses during dump did not exceed 2.1 bar and was mostly driven by the AC losses. The estimated velocity of the normal zone propagation was about $0.4 \mathrm{~m} / \mathrm{s}$ down stream and $0.2 \mathrm{~m} / \mathrm{s}$ upstream.

This performance demonstrates that a protective discharge in a fusion machine can be handled smoothly with short downtimes and without any major interruption of cryogenic services.

B. Observation of thermohydraulic quench back

During the ramp rate limitation study of the CS Insert at elevated temperature we observed a very fast propagation of the normal zone. The CS Insert temperature was set at $7.5 \mathrm{~K}$ and the $\mathrm{dB} / \mathrm{dt}$ of the ramp was $0.4 \mathrm{~T} / \mathrm{s}$. The quench occurred at about $44 \mathrm{kA}$ and due to proximity to the critical current, a pressure wave and associated adiabatic temperature rise in the wave occurred. The propagation of the normal zone was two orders of magnitude faster than in the quench initiated at $4.5 \mathrm{~K}$ at similar currents. Both downstream velocity and the upstream velocity were about $80 \mathrm{~m} / \mathrm{s}$. The peak pressure in this event was estimated at about 60 bar. This behavior is a clear demonstration of the thermohydraulic "quench-back" phenomenon predicted by theory ${ }^{16-17}$ and observed experimentally ${ }^{18}$, where acceleration of the normal zone propagation increased by a factor of 7-8, when this effect was observed. In our case, more than two orders of magnitude acceleration of the normal zone propagation velocity was observed.

Thermohydraulic quench back attracted attention in the early 90 -s as a potential mechanism to spread the energy stored in the magnet over a significant volume during the quench event and therefore reduce the hot spot temperature in the magnet. As in ${ }^{18}$ we observed it only in the vicinity of the critical current and found difficult to handle such a violent quench due to unusually large heat deposition in the cryogenic circuit, resulting in activation of the relieve valves and venting significant amount of cold helium into the recovery system. More study is needed to ascertain if this phenomenon could be used in practice for better protection of large magnets and if it provides any advantages over the traditional protection scheme.

\section{CONCLUSIONS}

All of the main goals of the Test Program were achieved. Performance of the CSMC and CS Insert demonstrated that:

1. Large scale, high field magnets can be designed, built and operated with little or no degradation of superconducting properties.

2. High performance of the magnet fully justified the additional $R \& D$ and fabrication effort for the Incoloy 908 jacket used in the CSMC and in the CS Insert.

3. Many interesting phenomena were observed during CSMC and the CS Insert testing. Analysis of the data will bring our understanding of CICC performance to a higher level.

\section{ACKNOWLEDGMENT}

Well over a hundred people from many countries and organizations participated in this large and very successful project. The authors are grateful to all who contributed to this success.

\section{REFERENCES}

1. R.J. Jayakumar, J.V. Minervini, J. Wohlwend, N. Martovetsky, R. Thome, "The USHT-ITER CS Model Coil Program Achievements", IEEE Trans. Appl. Superconductivity, vol. 10, No 1, pp.560-563, March 2000.

2. T. Ando, T. Hiyama, Y. Takahashi, et .al, "Completion of the ITER CS Model Coil -Outer Module Fabrication”, ibid, pp. 568-571.

3. M. Sugimoto, T.Isono, Y.Nunoya et al, "Completion of CS Insert Fabrication", ibid, pp. 564-567

4. "Test Description Document for ITER Central Solenoid Model Coil", ITER Document, Rev. 3.2, June 1998.

5. S. Shimamoto, K. Hamada, T. Kato, et al, "Construction of ITER Common Test Facility for CS Model Coil, IEEE Trans. Mag., vol. 32, No. 4, p 3049, July 1996 
6. N. Mitchell et al, "Design Criteria:DDD1.1-1.3 Appendix C: Superconducting Magnet Design Criteria," ITER N11 DDD 32 97-1208 W 02, Dec 8, 1997.

7. L.T. Summers, M.W. Guinan, J.R. Miller, P.A. Hahn, “A Model for the Prediction of Nb3Sn Critical Current as a Function of Field Temperature, Strain, and Radiation Damage," IEEE Trans. MAG-27, No. 2, p.2041, (1991)

8. N. Martovetsky, J. Jayakumar, R. Manahan, P. Michael et al, "Development and Test of the ITER Conductor Joints for the central solenoid", Presented at the Annual American Nuclear Society meeting, Nashville, June 1998

9. Y. Takahashi, Y. Nunoya, G. Nishijima et al, "Development of 46-kA Nb3Sn Conductor Joint for ITER Model Coils", IEEE Trans. Appl. Superconductivity, vol. 10, No 1, pp.580-583, March 2000.

10. Takataro Hamajima, Satoshi Hanai, Yoshihiro Wachi, Nicolai Martovetsky et al "Test results of the 100 kWh SMES model coil AC loss performance," Cryogenics 39 (11) (1999) pp. 947-953.

11. D. Ciazynski, B. Turck, J.L. Duchateau, C. Meuris, "Current Distribution in 40kA NbTi and Nb3Sn Conductors for NET/ITER", IEEE Trans. MAG., vol. 27, No. 2, pp 2194, March 1991

12. P. Bruzzone, A.M. Fuchs, G. Vecsey, E.Zapretilina, 'Test results for the high field conductor of the ITER Central Solenoid Model Coil" Presented at CEC conference, Montreal, July 13-16, 1999.

13. Y. Takahashi, "Results of the CS conductor JAERI tests", private communication

14. E.P. Balsamo, D.Ciazynski, O.Cicchelli et al, "Direct measurement of the AC loss of an ITER relevant coil", Physica C 310 (1998) p.258-261

15. A. Nijhuis, N.H.W. Noordman, H.H.J. ten Kate et al., "Electromagnetic and Mechanical Characterization of ITER CS-MC Conductors affected by Transverse Cyclic Loading, Part 1: Interstrand Coupling Losses", IEEE Trans. Appl. Superconductivity, vol. 9, No 2, pp.1069-1072, June 1999.

16. L.Dresner, "Theory of thermal hydraulic quenchback in cable-in-conduit superconductors", Cryogenics, Vol. 31, pp.557-561, July 1991

17. C.A. Luongo, R.J. Loyd, F.K. Chen, and S.D. Peck, "Thermal-Hydraulic Simulation of Helium Expulsion from a Cable-in-Conduit Conductor," IEEE Transactions on Magnetics, vol. 25, no.2, pp. 1589-1595, 1989

18. J.W.Lue, L.Dresner, S.W.Schwenterly et al, "Investigating thermal hydraulic quenchback in a cable-in-conduit superconductor", IEEE Trans. Appl. Superconductivity, vol. 3, No 1, pp.338-341, March 1993 